\title{
Adverse event reporting systems and safer healthcare
}

\author{
James B Battles, David P Stevens
}

At the heart of improvement and safety in healthcare is the now-familiar tenet that was espoused decades ago by Demming and paraphrased by Berwick. ${ }^{1}$ Need we repeat it again? Every defect should lead to improvement processes that make care safer. It is time to deliver on the promise of reporting systems in patient safety.

While it is clear that event-reporting systems are now central elements in effective patient safety systems, their growth and implementation have been slow, and their effective use for implementing strategies for safer care has been even slower. In the decade since the report of the Institute of Medicine (IOM) to Err is Human ${ }^{2}$ released in 1999, and an Organization with a Memory ${ }^{3}$ published in 2000, consensus has grown that learning from patient safety events is an essential part of creating safer healthcare systems - at both national and local levels.

\section{IMPLEMENTING REPORTING SYSTEMS IS FREIGHTED WITH NATIONAL AS WELL AS LOCAL ISSUES}

This journal has devoted many pages to the implementation of various event detection or reporting systems. There have been a number of large-scale event reporting systems developed such as those found in the US Veteran's Administration, national systems in the UK and Demark, and state-based systems in the USA and Australia. Much of the literature on reporting systems has been descriptive in nature..$^{4-6}$ The absence of consensus surrounding the best process is an academic as well as political exercise among policy makers, but this absence of consensus should not hold back efforts to implement the most effective system that is at hand. Choices include spontaneous active reporting by front line care givers, indicators from administrative data,

Agency for Healthcare Research and Quality (AHRO), Center for Quality Improvement and Patient Safety (CQulPS), Rockville, Maryland, USA

Correspondence to: Dr James B Battles, Agency for Healthcare Research and Quality (AHRO), Center for Quality Improvement and Patient Safety (CQuIPS), 540 Gaither Road, Rockville, MD 20850, USA;

james.battles@ahrq.hhs.gov audits of clinical charts and triggers from medical record systems. ${ }^{78}$

It is regrettable that the process of developing a national approach for reporting in some countries has been painfully slow-as has been the case-for example, in the USA. Safety culture can be said to be a national issue as well as a local institutional matter. For example, legislative hearings regarding reporting systems began in the USA in January 2000 immediately following the publication of To Err is Human. However, legislation to spur an effective national approach was not enacted until July 2005. Still further delays were encountered in promulgating final regulations, which would become effective in January 2009. Shojania, in a recent commentary in QSHC, summarised many of the difficulties with reporting techniques and pointed out that regardless of burgeoning technology, inadequate reporting often has more to do with human rather than electronic components of systems. ${ }^{9}$

\section{HOPEFUL TRENDS}

Experience in the UK suggests there is reason for hope. The report by Hutchinson et al in this issue of $Q S H C^{10}$ describes an enhanced patient safety culture in those hospitals that demonstrated a more consistent reporting record (see page 5). The National Reporting and Learning System, established in England and Wales in 2003, had by 2007 over one million reports, and the pace continues to accelerate.

It is apparent from extensive and valuable work that, while national reporting systems offer promise, reporting must be accompanied by real change and improvement that uses what we know to address what we find by such measurement systems. Results-based articles are beginning to appear in the peer-reviewed literature based on the study of large numbers of reported events. Benn et $a^{11}$ in this issue provide an extensive review of the processes for feedback when effective reporting systems are in place (see page 11).

Patients and scholars of patient safety alike would say it is about time. The most compelling challenge to operators of existing reporting systems is to mine their data and publish learnings from their systems. While alerts and local newsletters are of value, the peer-reviewed literature needs more results-based articles and publications on what is learnt from event reports.

\section{"EVERY DEFECT IS A TREASURE"}

Repeating this epigram is all well and good, ${ }^{1}$ but its familiarity only emphasises the persistent urgency for development of safer systems for feedback as well as detection. For example, the knowledge to reduce or even eliminate surgical site, ventilatorrelated or central line infections compels us to track these events so that they are indeed eliminated. The report by Hutchinson et $a l^{10}$ and the summary of evidence by Benn et a ${ }^{11}$ offer compelling evidence that detection and reporting systems are now essential parts of safer healthcare systems and that there is urgency to harnessing the technology, culture, knowledge and human commitment to harvest these data for ever safer systems. ${ }^{11}$

\section{Competing interests: None.}

Qual Saf Health Care 2009;18:2.

doi:10.1136/qshc.2008.031997

\section{REFERENCES}

1. Berwick D. Continuous improvement as an ideal in healthcare. N Engl J Med 1989;320:53-6.

2. Kohn LT, Corrigan JM, Donaldson MS, eds. To err is human; building a safer health system. Washington: National Academy Press, 2000

3. Department of Health. An organization with a memory. Report of an expert group on learning from adverse events in the NHS chaired by the Chief Medical Officer (the NHS Report). London: The Stationery Office, 2000.

4. Battles JB, Lilford RJ. Organizing patient safety research to identify risks and hazards. Qual Saf Health Care 2003;12(II Suppl):ii2-7.

5. Aspden P, Corrigan JM, Wolcott J, et al., eds. Patient safety: achieving a new standard of care. Washington: The National Academies Press, 2004.

6. Beckmann U, West LF, Groombridge GJ, et al. The Australian Incident Monitoring Study in Intensive Care: AIMS-ICU. The development and evaluation of an incident reporting system in intensive care. Anaesth Intens Care 1996;24:314-19.

7. Battles JB, Kaplan HS, van der Schaaf TW, et al. The attributes of medical event reporting systems: experience with a prototype medical event reporting system for transfusion medicine. Arch Pathol Lab Med 1998;122:3;231-8.

8. Bagian JP, Lee C, Gosbee J, et al. Developing and deploying a patient safety program in a large health care delivery system: you can't fix up what you don't know about. Jt Comm J Qual Improve 2001;27;522-32.

9. Shojania KG. The frustrating case of incidentreporting systems. Qual Saf Health Care 2008;17:400-2.

10. Hutchinson A, Young TA, Cooper KL, et al. Trends in healthcare incident reporting and relationship to safety and quality data in acute hospitals: results from the National Reporting and Learning System. Oual Saf Health Care 2009;18:5-10.

11. Benn J, Koutantji M, Wallace L, et al. Feedback from incident reporting: information and action to improve patient safety. Qual Saf Health Care 2009;18:11-21. 